\title{
Multi-regression prediction model for surface roughness and tool wear in turning novel aluminum alloy (LM6)/fly ash composite using response surface and central composite design methodology
}

\author{
Smita Rani Panda ${ }^{\mathrm{a}}$, Ajit Kumar Senapati ${ }^{\mathrm{b}}$ and Purna Chandra Mishra ${ }^{\mathrm{b}^{*}}$
}

${ }^{a}$ Department of Mechanical Engineering, Rajdhani Engineering College, Bhubaneswar, Odisha, India ${ }^{b}$ School of Mechanical Engineering, KIIT University, Bhubaneswar - 751024, Odisha, India

CHRONICLE ABSTRACT

\section{Article history:}

Received Februray 42016

Received in Revised Format

June 162016

Accepted July 282016

Available online

August 12016

Keywords:

Aluminum alloy matrix

Fly ash

Turning

Response surface method

Central composite design

\begin{abstract}
Turning experiments were conducted on a novel aluminum alloy (LM6)/fly ash composite based on the response surface and face centered central composite design methodology. The effects of cutting parameters on surface roughness and tool wear were investigated. Multiple regression models were developed for the responses and the adequacies of the developed models were tested at $95 \%$ confidence interval using the analysis of variance (ANOVA) technique. Carbide inserts (Model: CNMG 120408-M5) were used for turning the specimens in a CNC turning machine (model: LT-16). The test for significance of the regression models, the test for significance on individual model coefficients and the lack-of-fit tests were performed using the statistical Design-Expert7.0v software environments. R2 indicated the model significance and the value was more than $97 \%$, revealed that the relation between cutting responses and input parameters held good for more than $97 \%$ and the model was adequate.
\end{abstract}

\section{Introduction}

Waste fly ash reinforced aluminum matrix composites (AMC) are significant for their light weight, superior tribological properties, low material costs, savings in ash disposal costs, energy savings, environmental benefits and good corrosion resistance behavior (Rohatgi et al., 2006), for which they are increasingly being used in automobile, marine and aerospace industries (Anasyida et al., 2010).Due to some enormous properties like high wear resistance, low thermal expansion coefficient, good corrosion resistance, and improved mechanical properties at a wide range of temperatures, the Al-Si alloy was normally selected as matrix material (Saheb et al., 2001). Some researchers evaluated the mechanical properties (Rohatgi et al., 2002; Bienias et al., 2003; Zuoyong Dou et al., 2007), thermal properties (Rohatgi et al., 2006), damping properties (Wu et al., 2006) and tribological properties (Surappa, 2008) with the use of fly ash as reinforcement in aluminum matrix composites (Senapati et al., 2015). However, these are difficult-to-machine materials due to the presence of very hard and brittle reinforcements, which * Corresponding author. Tel.: +91 6746540805 (O)

E-mail: pcmishrafme@kiit.ac.in (P.C. Mishra)

(C) 2017 Growing Science Ltd. All rights reserved. doi: $10.5267 /$ j. ijiec.2016.8.001 
also leads to their poor machinability involving high tool wear and surface imperfections (Li \& Seah, 2001;Manna \& Bhattacharyya, 2005). Sahoo et al. (2013) presented the development of Al/SiCp (10\%weight) metal matrix composite through a conventional casting process and studied its machinability characteristics in turning using multi-layer TiN coated carbide insert under dry environment based on Taguchi'sL9 orthogonal array. Abrasion was found to be the dominant wear mechanism from the experimental study. Udaya Prakash et al. (2013) investigated the effect of parameters like gap voltage, pulse on time, pulse off time, wire feed and percentage of reinforcement on the response material removal rate as well as surface roughness while machining A1413/fly ash/boron carbide hybrid composite using wire electrical discharge machining. Shanmugha Sundaram and Subramanian (2013) experimentally investigated on the surface roughness of pure commercial Al, Al-15 $\mathrm{wt} \%$ fly ash, and Al- $15 \mathrm{wt} \%$ fly ash $/ 1.5 \mathrm{wt} \%$ graphite (Gr) composites produced by modified two-step stir casting. The effect of reinforcements and machining parameters such as cutting speed, feed rate, and depth of cut on surface roughness, which greatly influence the performance of the machined product, were analyzed during turning operation. Rao et al., (2014) investigated the machining behavior of A16061-flyash composite in Jobber XL CNC by using M2 grade HSS and K10 grade carbide inserts as cutting tools. The investigated result conclude that the increased fly ash content in the composites of A16061 reduces the premature failure of the cutting tool by reducing built up edge formation. K10 grade carbide insert cutting tool is preferred for machining of the A16061-flyash than that of M2 grade HSS. Charles et al., (2006) developed a mathematical model for machining of hybrid aluminum composites reinforced with $\mathrm{SiC}$ and fly ash particles using five level factorial design concepts. They used analysis of variance (ANOVA) technique to calculate the regression coefficients as well as to check the significance of the developed model. They observed that surface roughness increased with increasing the vol. \% of SiC particles and current but decreased with increase in pulse duration. Banerjee et al., (2008) used a face centered central composite design approach to develop a mathematical model for material removal rate and surface roughness. A total eighteen experiments were conducted based on the design matrix and the model was found to be adequate. According to the model developed, the surface roughness increased when the pulse on time was increased. Mishra et al., (2015) reported the ANOVA results for grey relational grade indicated that feed was the only significant machining process parameter for the multi-response characteristics under consideration.

This paper describes the mathematical model developed by Multiple Linear Regression Analysis to predict the machinability characteristics at $95 \%$ confidence level by response surface and face centered central composite methodology. The results are analyzed using ANOVA technique, i.e. average surface roughness $(\mathrm{Ra})$ and tool wear $\left(\mathrm{VB}_{\mathrm{c}}\right)$, while turning the composite in dry environment for the same machining parameters.

\section{Materials \& Methods}

Aluminum-silicon alloy(LM6) matrix composite reinforced with 15 wt. \% flyash (of average particle size $19.338 \mu \mathrm{m}$ ) was used as work material for turning. Chemical composition test result of the matrix alloy and reinforcement are shown in Table 1 and Table 2.

Table 1

Composition of Al-Si alloy [wt. \%] designated as matrix

\begin{tabular}{ccccccccccccc}
\hline Si & $\mathbf{C o}$ & $\mathbf{F e}$ & $\mathbf{C u}$ & $\mathbf{M n}$ & $\mathbf{T i}$ & $\mathbf{Z n}$ & $\mathbf{N i}$ & $\mathbf{S n}$ & $\mathbf{C r}$ & $\mathbf{C a}$ & $\mathbf{V}$ & Al \\
\hline 12.25 & 0.0174 & 0.4353 & 0.08 & 0.1601 & 0.0672 & 0.0944 & 0.0264 & 0.0632 & 0.0199 & 0.0082 & 0.0146 & 86.7654 \\
\hline
\end{tabular}

Table 2

Chemical composition of waste fly ash collected from thermal power plant

\begin{tabular}{cccccccc}
\hline Compound & $\mathrm{SiO}_{2}$ & $\mathrm{Al}_{2} \mathrm{O}_{3}$ & $\mathrm{Fe}_{2} \mathrm{O}_{3}$ & $\mathrm{CaO}$ & $\mathrm{MgO}$ & $\mathrm{Na}_{2} \mathrm{O}$ & $\mathrm{K}_{2} \mathrm{O}$ \\
\hline (Wt. \%) & 63.34 & 24.60 & 4.97 & 1.23 & 0.56 & 0.11 & 0.64 \\
\hline
\end{tabular}


For the as received flyash, the micrograph measured by Scanning Electron Microscope (Make: JEOL, Model: JSM-6480LV) and particle size measured by particle size analyzer, (Make: Malvern, Model Micro-P) as shown in Fig.1.

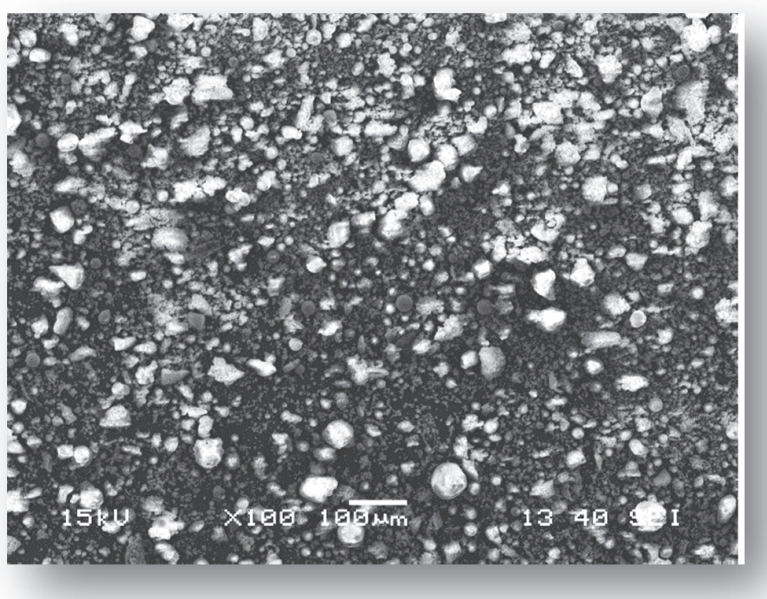

(a)

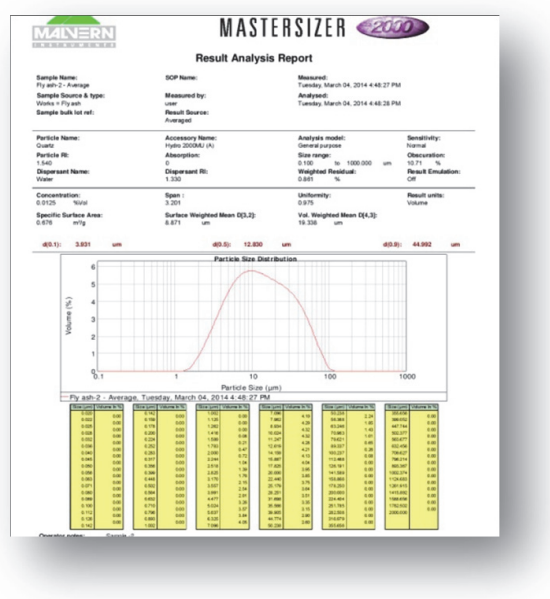

(b)

Fig. 1. (a) SEM micrograph and (b) Particle size analysis of as received waste flyash

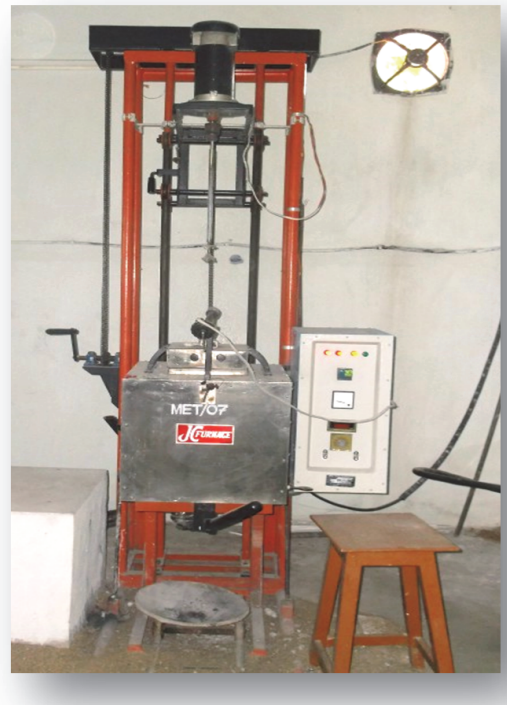

(a)

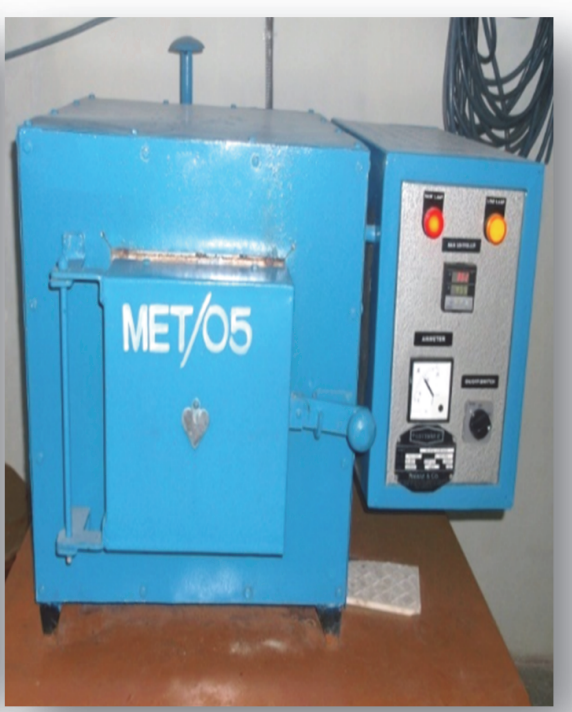

(b)

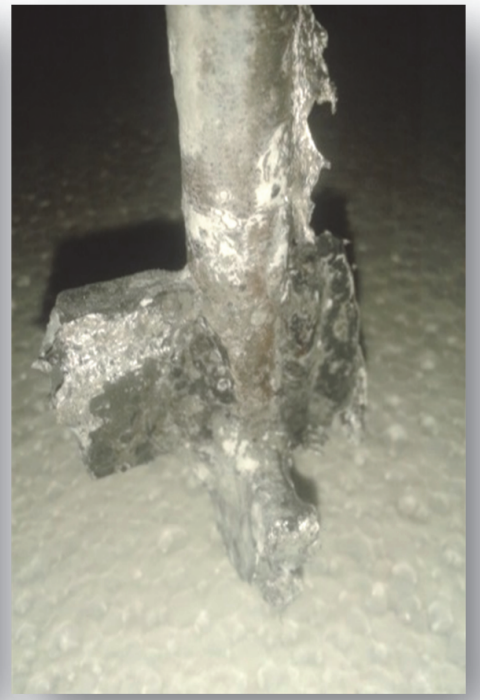

(c)

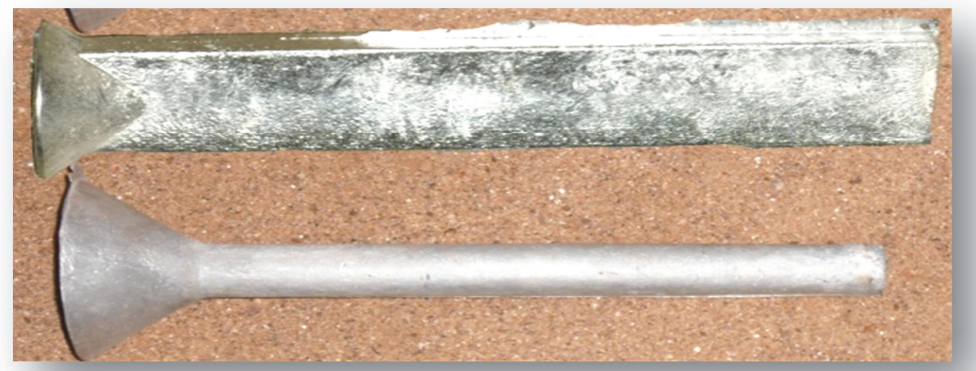

(d)

Fig. 2. The components of composite fabrication (a) bottom pouring furnace, (b) muffle furnace, (c) BN coated stainless steel stirrer and (d) cast composite 
The composite was fabricated by conventional stir casting method in an electrical resistance furnace, mounted with a speed regulated stirring system and temperature controller. The components of the composite fabrication setup are shown in Fig. 2. As received Al-Si alloy ingots were cleaned properly to eliminate the surface impurities and cut into proper sizes. The proper sizes of Al-Si alloy are weighed in requisite quantities and are charged into a vertically aligned pit type bottom poured melting furnace. Flyash was preheated to $650^{\circ} \mathrm{C} \pm 5^{\circ} \mathrm{C}$ before pouring in to the melt of aluminum-silicon alloy by using muffle furnace to remove residual moisture and to improve wetability. The pit type bottom pouring furnace temperature was first raised above the liquidus temperature of $\mathrm{Al}-\mathrm{Si}$ alloy near about $750^{\circ} \mathrm{C}$ to melt the Al-Si alloy completely and was then cooled down just to below the liquidus to keep the slurry in semi-solid state. An argon atmosphere was maintained in the furnace throughout the process so as to avoid the pre-oxidation. The molten metal was stirred with a boron nitride $(\mathrm{BN})$ coated stainless steel rotor at a speed of 600-650 rpm.

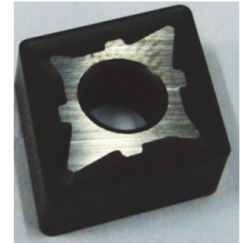

(a)

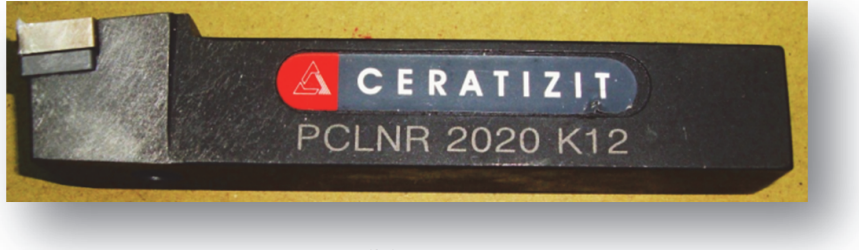

(b)

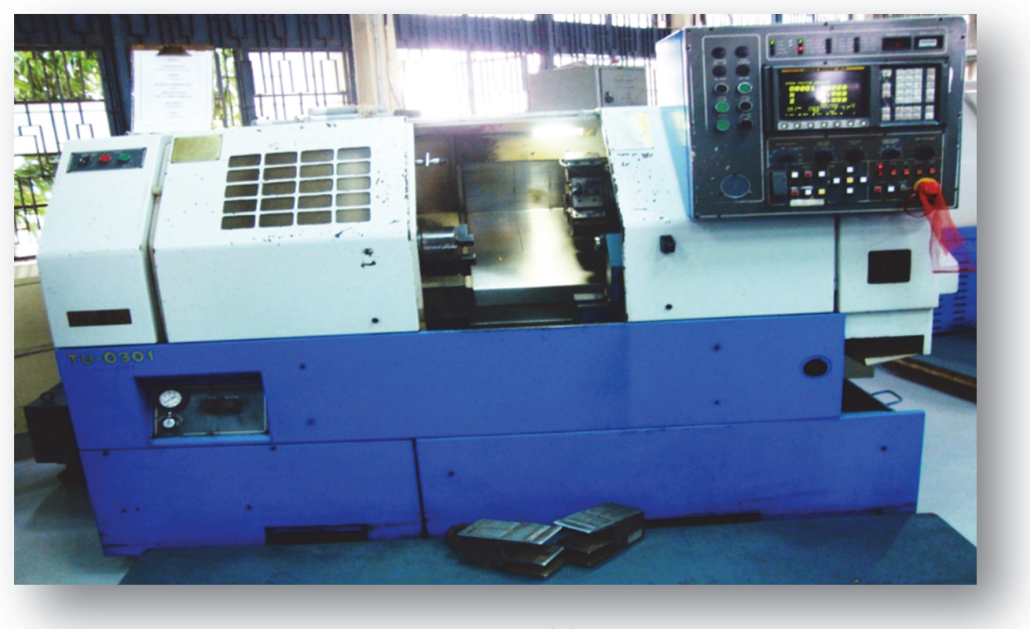

(c)

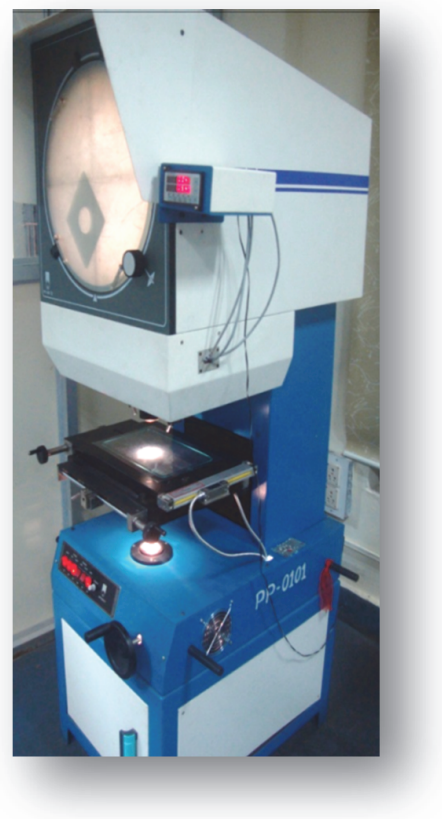

(d)

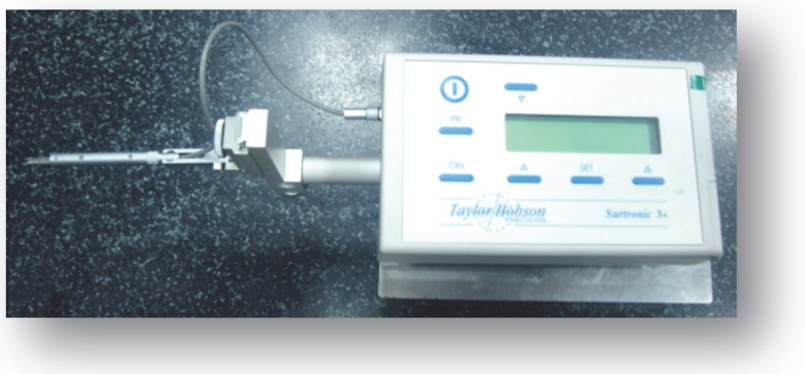

(e)

Fig. 4. The components of machining setup (a) carbide insert (CNMG 120408-M5), (b) tool holder (PCLNR2020K12), (c) CNC Lathe (Model LT-16 CNC), (d) Tool Profile Projectors (PP 400 TE) and (e) surface roughness tester (Taylor Hobson, Surtronic 3+).

A vortex was created in the melt because of stirring where the preheated flyash was poured centrally into the vortex. The rotor is moved down slowly, from top to bottom by maintaining clearance of $12 \mathrm{~mm}$ from 
the bottom. The rotor was then pushed back slowly to its initial position. The pouring temperature of the liquid is kept around $700^{\circ}$ C.Casting was made in cylindrical (i.e, diameter: $30 \mathrm{~mm}$ and length: $300 \mathrm{~mm}$ metal moulds. The melt was allowed to solidify in the moulds and cooled to room temperature. Scanning electron microscopy (SEM) graph along with energy dispersive X-ray spectroscopy (EDAX) analysis confirms the presence of unreacted carbon in the matrix as shown in Fig.3. A notable difference is observed in optical micro graphs of virgin Al-Si alloy and AMC reinforced with fly ash. Turning experiments were conducted by a CNC lathe(Make: ACE Designers, Model LT-16) with an accuracy level of 10 microns and carbide inserts of geometry CNMG 120408-M5, manufactured by SECO where main composition is tungsten carbide $94 \% \mathrm{WC}$ and cobalt $6 \% \mathrm{Co}$ as binder. The inserts are rigidly mounted on a right hand style tool holder designated by ISO as PCLNR2020K12.Experiments were conducted in dry machining environments. Fig. 4 depicts the turning setup in dry machining environment. Machining process parameters and their levels used for turning the composite are presented in Table 3.

Table 3

Design layout of independent variables and their levels for machinability studies

\begin{tabular}{lllccccc}
\hline Process variables & Notation & Unit & \multicolumn{5}{c}{ Levels } \\
\hline Cutting Speed & & & $-\alpha$ & -1 & 0 & +1 & $+\alpha$ \\
Feed rate & $s$ & $\mathrm{~m} / \mathrm{min}$ & 70 & 90 & 120 & 150 & 170 \\
Depth of cut & $f$ & $\mathrm{~mm} / \mathrm{rev}$ & 0.02 & 0.07 & 0.14 & 0.21 & 0.26 \\
\hline
\end{tabular}

\section{Design of experiments}

In machining, the influence of cutting speed, feed rate and depth of cut on cutting tool wear behavior of virgin Al-Si alloy and metal matrix composite prepared with fly ash was investigated. The turning experiments were conducted based upon the combined response surface (RS) and face centered Central Composite Design (CCD) methodology. In the response surface methodology (RSM), the quantitative form of relationship between desired response and independent input parameters could be represented as (Montgomery, 1990).

$$
y=f\left(x_{1}, x_{2}, x_{3}, \ldots x_{n}\right) \pm e r r,
$$

where $y$ is the desired response, $f$ is the response function (or response surface), $x_{1}, x_{2}, x_{3} \ldots x_{\mathrm{n}}$ are the independent input parameters and err is fitting error. The approximation of $f$ will be proposed using the fitted second order polynomial regression model, called the quadratic model. The quadratic model of $f$ can be written as following (Montgomery \& Peck, 1992).

$$
Y=b_{0}+\sum_{i=1}^{k} b_{i} X_{i}+\sum_{i=1}^{k} b_{i i} X_{i}^{2}+\sum_{i=1}^{k} b_{i j} X_{i} X_{j} \pm \text { err }
$$

where $Y$ is the corresponding response and $X_{\mathrm{i}}$ are the values of the $i^{\text {th }}$ machining process parameters. The terms $b \ldots$ are the regression coefficients and the residual err measures the experimental error of the observations. This assumed surface $Y$ contains linear, squared and cross product terms of parameters $X_{i}$ 's. In order to estimate the regression coefficients a number of experimental design techniques are available. Box and Hunter (1957) have proposed that scheme based on central composite rotatable design fits the second order response surface very accurately. Let the points $(0,0 \ldots 0)$ represent the centre of the region in which the relation between $Y$ and $X$ is under investigation. From the result of any experiment the standard error, err of $Y$ can be computed at any point on the fitted surface. This standard error will be a function of the co-ordinates $X_{i}$ 's of the point. Due to rotatability condition this standard error is same at all equidistance points with the distance $\rho$ from the centre of the region i.e. for all points for which (Cochran \& Cox, 1962):

$$
X_{1}^{2}+X_{2}^{2}+\cdots+X_{k}^{2}=\rho^{2}=\text { Constant }
$$


The components of Central Composite Second Order Rotatable Design for different number of variables are shown in Table 4.

Table 4

Face centered central composite design matrix

\begin{tabular}{cccc}
\hline Exp. No. & Actual Variables & \\
\cline { 2 - 5 } & $\begin{array}{c}\text { Cutting Speed, } \\
\text { s (m/min) }\end{array}$ & $\begin{array}{c}\text { Feed rate, } \\
\text { f(mm/rev })\end{array}$ & $\begin{array}{r}\text { Depth of cut, } \\
\mathrm{d}(\mathrm{mm})\end{array}$ \\
\hline 1 & -1 & -1 & -1 \\
2 & +1 & -1 & -1 \\
3 & -1 & +1 & -1 \\
4 & +1 & +1 & -1 \\
5 & -1 & -1 & +1 \\
6 & +1 & -1 & +1 \\
7 & -1 & +1 & +1 \\
8 & +1 & +1 & +1 \\
9 & $-\alpha$ & 0 & 0 \\
10 & $+\alpha$ & 0 & 0 \\
11 & 0 & $-\alpha$ & 0 \\
12 & 0 & $+\alpha$ & $-\alpha$ \\
13 & 0 & 0 & $+\alpha$ \\
14 & 0 & 0 & 0 \\
15 & 0 & 0 & 0 \\
16 & 0 & 0 & 0 \\
17 & 0 & 0 & 0 \\
18 & 0 & 0 & 0 \\
19 & 0 & 0 & 0 \\
20 & 0 & 0 & \\
\hline
\end{tabular}

Design Expert Software version 7.0 is used to develop the experimental plan for RSM. During machinability study, the machining parameters such as the cutting speed $(s)$, feed rate $(f)$ and depth of cut $(d)$ are selected as the independent input variables. The desired responses are the surface roughness $(\mathrm{Ra})$ and tool wear $(\mathrm{VBc})$ which are assumed to be affected by the above three principal machining parameters. The response surface methodology is engaged for modeling and analyzing the machining parameters in the turning process so as to obtain the machinability performances in terms of surface roughness $(\mathrm{Ra})$ and flank wear $(\mathrm{VBc})$. A rotatable central composite design is selected for the experimentations. It is the most extensively used experimental design for the modeling a second - order response surface. For a given number of variables, the required to achieve ratability is computed where $n_{f}$ is the number of points in the $2 k$ factorial design ( $k$ is the number of factors). Rotability refers to the uniformity of prediction error. In rotatable designs, all points at the same radial distance $(r)$ from the center point have the same magnitude of prediction error. A rotatable CCD consists of $2 \mathrm{k}$ fractional factorial points, augmented by $2 k$ axial points and $n_{c}$, centre points $(0,0,0,0 \ldots, 0)$ the centre points vary from three to six. In this experimentation, eight $(2 \times 3)$ factorial points, six axial points $(2 \times 3)$ and six centre runs, a total of 20 experimental runs have been considered. A randomized experimental run has been carried out to minimize the error due to machining set-up and the regression models were obtained and analyzed using analysis of variance (ANOVA).

\section{Results and discussion}

\subsection{Experimental data}

The turning experiments were conducted, with three levels of cutting parameters as provided in Table 3 to investigate the their effect on the surface roughness and tool wear as the responses. The experimental data are presented in Table 5. 
Table 5

Experimental results obtained in machining Al-Si alloy and composite samples

Exp No Cutting Speed Feed Depth of Cut Surface Roughness (SR in $\mu \mathrm{m})$
(s), $\mathrm{m} / \mathrm{min})$
(f), $(\mathrm{mm} / \mathrm{rev})$
(d in $\mathrm{mm})$

(TW in $\mathrm{mm}$ )

\begin{tabular}{cccc} 
Al-Si & AMC & Al-Si & AMC \\
\hline 1.98 & 1.38 & 0.052 & 0.072 \\
1.43 & 1.12 & 0.132 & 0.151 \\
5.15 & 4.68 & 0.079 & 0.098 \\
2.89 & 2.23 & 0.203 & 0.223 \\
2.1 & 1.63 & 0.051 & 0.069 \\
1.72 & 1.25 & 0.139 & 0.160 \\
5.32 & 4.85 & 0.081 & 0.098 \\
3.37 & 2.9 & 0.205 & 0.226 \\
4.44 & 3.97 & 0.034 & 0.073 \\
2.67 & 2.2 & 0.217 & 0.285 \\
0.85 & 0.38 & 0.088 & 0.1 \\
4.74 & 4.23 & 0.128 & 0.197 \\
2.04 & 1.57 & 0.108 & 0.121 \\
2.49 & 2.02 & 0.116 & 0.127 \\
3.46 & 2.99 & 0.104 & 0.116 \\
3.46 & 2.99 & 0.105 & 0.121 \\
3.48 & 3.01 & 0.104 & 0.119 \\
3.46 & 2.99 & 0.103 & 0.114 \\
3.46 & 2.99 & 0.105 & 0.115 \\
3.46 & 2.99 & 0.104 & 0.116 \\
\hline
\end{tabular}

\subsection{Multiple regression predictive models for surface roughness and tool wear}

\subsubsection{Selection of adequate model}

The adequacy of the model for Al-Si Alloy and AMC prepared with fly ash, was decided by performing sequential model sum of squares. Table 6 and Table 7 show the sequential model sum of squares test data for two different materials to select an adequate model to fit the surface roughness and tool wear. The sequential model sum of squares test in each table shows, how the terms of increasing complexity contribute to the model. Results from Tables 6 and Table 7 indicated quadratic models for surface roughness and tool wear of the test samples.

\section{Table 6}

Selection of adequate model for surface roughness

\begin{tabular}{|c|c|c|c|c|c|c|}
\hline \multicolumn{7}{|c|}{ Sequential Model Sum of squares ( Al-Si Alloy) } \\
\hline Source & $\begin{array}{l}\text { Sum of } \\
\text { Squares }\end{array}$ & df & $\begin{array}{l}\text { Mean } \\
\text { Square }\end{array}$ & $\begin{array}{c}\text { F } \\
\text { Value }\end{array}$ & $\begin{array}{c}\text { p-value } \\
\text { Prob }>\text { F }\end{array}$ & \\
\hline Mean vs Total & 192.014 & 1 & 192.014 & & & \\
\hline Linear vs Mean & 23.90991 & 3 & 7.96997 & 29.612 & $<0.0001$ & \\
\hline 2FI vs Linear & 1.3808 & 3 & 0.460267 & 2.045248 & 0.1572 & \\
\hline Quadratic vs 2FI & 2.793803 & 3 & 0.931268 & 70.68854 & $<0.0001$ & Suggested \\
\hline Cubic vs Quadratic & 0.050441 & 4 & 0.01261 & 0.930622 & 0.5050 & Aliased \\
\hline Residual & 0.081302 & 6 & 0.01355 & & & \\
\hline Total & 220.2303 & 20 & 11.01152 & & & \\
\hline \multicolumn{7}{|c|}{ Sequential Model Sum of squares (MMC-UFA) } \\
\hline Mean vs Total & 137.1308 & 1 & 137.1308 & & & \\
\hline Linear vs Mean & 23.16737 & 3 & 7.722456 & 25.57164 & $<0.0001$ & \\
\hline 2FI vs Linear & 1.8117 & 3 & 0.6039 & 2.599409 & 0.0967 & \\
\hline Quadratic vs 2FI & 2.865819 & 3 & 0.955273 & 61.88273 & $<0.0001$ & Suggested \\
\hline Cubic vs Quadratic & 0.085682 & 4 & 0.02142 & 1.871157 & 0.2348 & Aliased \\
\hline Residual & 0.068686 & 6 & 0.011448 & & & \\
\hline Total & 165.1301 & 20 & 8.256505 & & & \\
\hline
\end{tabular}


Table 7

Selection of adequate model for tool wear

\begin{tabular}{|c|c|c|c|c|c|c|}
\hline \multicolumn{7}{|c|}{ Sequential model sum of squares (Al-Si Alloy) } \\
\hline Source & $\begin{array}{l}\text { Sum of } \\
\text { Squares }\end{array}$ & $\mathrm{df}$ & $\begin{array}{c}\text { Mean } \\
\text { Square }\end{array}$ & $\begin{array}{c}\text { F } \\
\text { Value }\end{array}$ & $\begin{array}{c}\text { p-value } \\
\text { Prob }>\text { F }\end{array}$ & \\
\hline Mean vs Total & 0.254928 & 1 & 0.254928 & & & \\
\hline Linear vs Mean & 0.043396 & 3 & 0.014465 & 97.99664 & $<0.0001$ & Suggested \\
\hline 2FI vs Linear & 0.000809 & 3 & 0.00027 & 2.255564 & 0.1303 & \\
\hline Quadratic vs 2FI & 0.001001 & 3 & 0.000334 & 6.045833 & 0.0129 & Suggested \\
\hline Cubic vs Quadratic & 0.000537 & 4 & 0.000134 & 55.37661 & $<0.0001$ & Aliased \\
\hline Residual & $1.46 \mathrm{E}-05$ & 6 & $2.43 \mathrm{E}-06$ & & & \\
\hline Total & 0.300686 & 20 & 0.015034 & & & \\
\hline \multicolumn{7}{|c|}{ Sequential model sum of squares (AMC) } \\
\hline Mean vs Total & 0.36477 & 1 & 0.36477 & & & \\
\hline Linear vs Mean & 0.05381 & 3 & 0.017937 & 36.57428 & $<0.0001$ & \\
\hline 2FI vs Linear & 0.00089 & 3 & 0.000297 & 0.554644 & 0.6541 & \\
\hline Quadratic vs 2FI & 0.005736 & 3 & 0.001912 & 15.66187 & 0.0004 & Suggested \\
\hline Cubic vs Quadratic & 0.000427 & 4 & 0.000107 & 0.806275 & 0.5637 & Aliased \\
\hline Residual & 0.000794 & 6 & 0.000132 & & & \\
\hline Total & 0.426427 & 20 & 0.021321 & & & \\
\hline
\end{tabular}

\subsubsection{Analysis of variance}

The adequacy of the developed models are tested at $95 \%$ confidence interval using the ANOVA technique, and the results of the quadratic order response surface model fitting in the form of ANOVA are given in Tables 8 and 9 for surface roughness and Tables 10 and 11 for tool wear in the tested Al-Si alloy and composite specimens respectively. Tables 8, 9, 10 and 11 show the values of coefficient of determination $\mathrm{R}^{2}$ are nearly equal to 1 . The adjusted coefficient of determination $\mathrm{R}^{2}$ is variation of the ordinary $\mathrm{R}^{2}$ statistic that reflects the number of factors in the model. The entire adequacy measures are closer to 1 , which is in reasonable agreement and indicate adequate models. The adequate precision 'Adeq Precision' compares the range of the predicted value at the design points to the average prediction error. Adequate precision measures signal to noise ratio. In the present data, the value of adequate precision is significantly greater than 4 which are desirable. The adequate precision ratio above 4 indicates adequate model discrimination. The experimental data also reveals an improved precision and reliability of the conducted experiments. Prediction error sum of squares (PRESS)values are considerably small.

Table 8

ANOVA results for Al-Si Alloy (surface roughness)

\begin{tabular}{ccccccc}
\hline Source & Sum of & df & Mean & $\mathrm{F}$ & $\mathrm{p}$-value & \\
\hline Model & 28.08451 & 9 & 3.120501 & 236.8639 & $<0.0001$ & significant \\
A-s & 4.824098 & 1 & 4.824098 & 366.1766 & $<0.0001$ & significant \\
B-f & 18.84412 & 1 & 18.84412 & 1430.376 & $<0.0001$ & significant \\
C-d & 0.241695 & 1 & 0.241695 & 18.34599 & 0.0016 & significant \\
AB & 1.3448 & 1 & 1.3448 & 102.078 & $<0.0001$ & significant \\
AC & 0.0288 & 1 & 0.0288 & 2.186084 & 0.1701 & \\
BC & 0.0072 & 1 & 0.0072 & 0.546521 & 0.4767 & \\
$A^{\wedge} 2$ & 0.062793 & 1 & 0.062793 & 4.766345 & 0.0540 & \\
$B^{\wedge} 2$ & 0.592071 & 1 & 0.592071 & 44.94155 & $<0.0001$ & significant \\
$\mathrm{C}^{\wedge} 2$ & 2.192797 & 1 & 2.192797 & 166.4458 & $<0.0001$ & significant \\
Residual & 0.131742 & 10 & 0.013174 & & & \\
Lack of Fit & 0.131409 & 5 & 0.026282 & & & \\
Pure Error & 0.000333 & 5 & $6.67 \mathrm{E}-05$ & & & \\
Cor Total & 28.21626 & 19 & & & & \\
\hline R-Squared=0.99533 & Std. Dev. $=0.11477$ & Adj R-Squared $=0.99112$ & Mean=3.0985 \\
Pred R-Squared= $=0.96461 \quad$ C.V. $\%=3.70434$ & Adeq Precision=53.03167 & PRESS=0.99856
\end{tabular}


Tables 8, 9, 10 and 11 also presents that the values of 'Probability $>$ F' in for all models are less than 0.0500, indicate that all the models are significant. The 'Lack-of-fit' value implies that the 'Lack-of-fit' is not significant relative to the pure error. From the above analysis, it has been asserted that the developed models are well within the limits and can be used for the prediction of responses.

Table 9

ANOVA results for Aluminum alloy matrix composite (surface roughness)

\begin{tabular}{|c|c|c|c|c|c|c|}
\hline Source & Sum of & $\mathrm{df}$ & Mean & $\mathrm{F}$ & p-value & \\
\hline Model & 27.84489 & 9 & 3.093876 & 200.4218 & $<0.0001$ & significant \\
\hline A-s & 4.705963 & 1 & 4.705963 & 304.853 & $<0.0001$ & significant \\
\hline B-f & 18.17527 & 1 & 18.17527 & 1177.396 & $<0.0001$ & significant \\
\hline C-d & 0.286139 & 1 & 0.286139 & 18.53616 & 0.0015 & significant \\
\hline $\mathrm{AB}$ & 1.7672 & 1 & 1.7672 & 114.4795 & $<0.0001$ & significant \\
\hline $\mathrm{AC}$ & 0.01805 & 1 & 0.01805 & 1.169282 & 0.3049 & \\
\hline $\mathrm{BC}$ & 0.02645 & 1 & 0.02645 & 1.713435 & 0.2198 & \\
\hline $\mathrm{A}^{\wedge} 2$ & 0.057709 & 1 & 0.057709 & 3.738429 & 0.0820 & \\
\hline $\mathrm{B}^{\wedge} 2$ & 0.650704 & 1 & 0.650704 & 42.15268 & $<0.0001$ & significant \\
\hline $\mathrm{C}^{\wedge} 2$ & 2.223579 & 1 & 2.223579 & 144.0438 & $<0.0001$ & significant \\
\hline Residual & 0.154368 & 10 & 0.015437 & & & \\
\hline Lack of Fit & 0.154035 & 5 & 0.030807 & & & \\
\hline Pure Error & 0.000333 & 5 & $6.67 \mathrm{E}-05$ & & & \\
\hline Cor Total & 27.99926 & 19 & & & & \\
\hline R-S & Std & & Ad. & $\mathrm{red}=0.98952$ & Uean $=2.6185$ & \\
\hline Pred R-Squared & $95561 \quad$ C.V & & Ade & ion $=49.67930$ & $\mathrm{RESS}=1.24281$ & \\
\hline
\end{tabular}

Table 10

ANOVA results for Al-Si alloy (tool wear)

\begin{tabular}{|c|c|c|c|c|c|c|}
\hline Source & $\begin{array}{l}\text { Sum of } \\
\text { Squares }\end{array}$ & $\mathrm{df}$ & $\begin{array}{l}\text { Mean } \\
\text { Square }\end{array}$ & $\begin{array}{c}\mathrm{F} \\
\text { Value }\end{array}$ & $\begin{array}{l}\text { p-value } \\
\text { Prob }>\text { F }\end{array}$ & \\
\hline Model & 0.045206 & 9 & 0.005023 & 90.98923 & $<0.0001$ & significant \\
\hline A-s & 0.038357 & 1 & 0.038357 & 694.8432 & $<0.0001$ & significant \\
\hline B-f & 0.004998 & 1 & 0.004998 & 90.54672 & $<0.0001$ & significant \\
\hline C-d & $4.03 \mathrm{E}-05$ & 1 & 4.03E-05 & 0.729683 & 0.4130 & \\
\hline $\mathrm{AB}$ & 0.0008 & 1 & 0.0008 & 14.49201 & 0.0034 & significant \\
\hline $\mathrm{AC}$ & $8 \mathrm{E}-06$ & 1 & $8 \mathrm{E}-06$ & 0.14492 & 0.7114 & \\
\hline $\mathrm{BC}$ & $5 \mathrm{E}-07$ & 1 & $5 \mathrm{E}-07$ & 0.009058 & 0.9261 & \\
\hline $\mathrm{A}^{\wedge} 2$ & 0.00091 & 1 & 0.00091 & 16.48645 & 0.0023 & significant \\
\hline $\mathrm{B}^{\wedge} 2$ & $4.46 \mathrm{E}-05$ & 1 & $4.46 \mathrm{E}-05$ & 0.808317 & 0.3898 & \\
\hline $\mathrm{C}^{\wedge} 2$ & 0.000145 & 1 & 0.000145 & 2.62973 & 0.1359 & \\
\hline Residual & 0.000552 & 10 & $5.52 \mathrm{E}-05$ & & & \\
\hline Lack of Fit & 0.000549 & 5 & 0.00011 & & & \\
\hline Pure Error & $2.83 \mathrm{E}-06$ & 5 & $5.67 \mathrm{E}-07$ & & & \\
\hline Cor Total & 0.045758 & 19 & & & & \\
\hline R-Squared $=0$ & Std. & .00742 & Adj F & ared $=0.97707$ & Mean $=0.1129$ & \\
\hline Pred R-Square & 0.90846 C.V & 8092 & Adeq & sion $=33.93013$ & PRESS $=0.00418$ & \\
\hline
\end{tabular}




\section{Table 11}

ANOVA results for Al-Si alloy matrix composite (tool wear)

\begin{tabular}{|c|c|c|c|c|c|c|}
\hline Source & $\begin{array}{l}\text { Sum of } \\
\text { Squares }\end{array}$ & df & $\begin{array}{l}\text { Mean } \\
\text { Square }\end{array}$ & $\begin{array}{c}\mathrm{F} \\
\text { Value }\end{array}$ & $\begin{array}{l}\mathrm{p} \text {-value } \\
\text { Prob }>\mathrm{F}\end{array}$ & \\
\hline Model & 0.060436 & 9 & 0.006715 & 55.00972 & $<0.0001$ & significant \\
\hline A-s & 0.044497 & 1 & 0.044497 & 364.5111 & $<0.0001$ & significant \\
\hline$B-f$ & 0.009287 & 1 & 0.009287 & 76.07826 & $<0.0001$ & significant \\
\hline C-d & $2.67 \mathrm{E}-05$ & 1 & $2.67 \mathrm{E}-05$ & 0.218615 & 0.6501 & \\
\hline $\mathrm{AB}$ & 0.000861 & 1 & 0.000861 & 7.054249 & 0.0241 & significant \\
\hline $\mathrm{AC}$ & $2.81 \mathrm{E}-05$ & 1 & $2.81 \mathrm{E}-05$ & 0.230397 & 0.6416 & \\
\hline $\mathrm{BC}$ & $1.13 \mathrm{E}-06$ & 1 & $1.13 \mathrm{E}-06$ & 0.009216 & 0.9254 & \\
\hline $\mathrm{A}^{\wedge} 2$ & 0.005053 & 1 & 0.005053 & 41.39707 & $<0.0001$ & significant \\
\hline $\mathrm{B}^{\wedge} 2$ & 0.000909 & 1 & 0.000909 & 7.447262 & 0.0212 & significant \\
\hline $\mathrm{C}^{\wedge} 2$ & $7.46 \mathrm{E}-06$ & 1 & $7.46 \mathrm{E}-06$ & 0.061133 & 0.8097 & \\
\hline Residual & 0.001221 & 10 & 0.000122 & & & \\
\hline Lack of Fit & 0.001186 & 5 & 0.000237 & & & \\
\hline Pure Error & $3.48 \mathrm{E}-05$ & 5 & $6.97 \mathrm{E}-06$ & & & \\
\hline Cor Total & 0.061657 & 19 & & & & \\
\hline \multicolumn{2}{|c|}{$\begin{array}{l}\text { R-Squared }=0.98020 \\
\text { Pred R-Squared }=0.85343\end{array}$} & $\begin{array}{l}\text { Std. Dev } \\
\text { C.V. } \%=\end{array}$ & $\begin{array}{ll}104 & \text { Adj } \\
12 & \text { Ade }\end{array}$ & $\begin{array}{l}\text { quared }=0 . \\
\text { ecision }=25\end{array}$ & $\begin{array}{l}38 \\
484\end{array}$ & Mean $=0.13505$ \\
\hline
\end{tabular}

\subsubsection{The developed predictive model}

The normal probability plots as shown in Figs. 5 and 6 for the surface roughness and Figs. 7 and 8 for the tool wear reveals that the residuals fall in a straight line i.e, the errors are distributed normally.
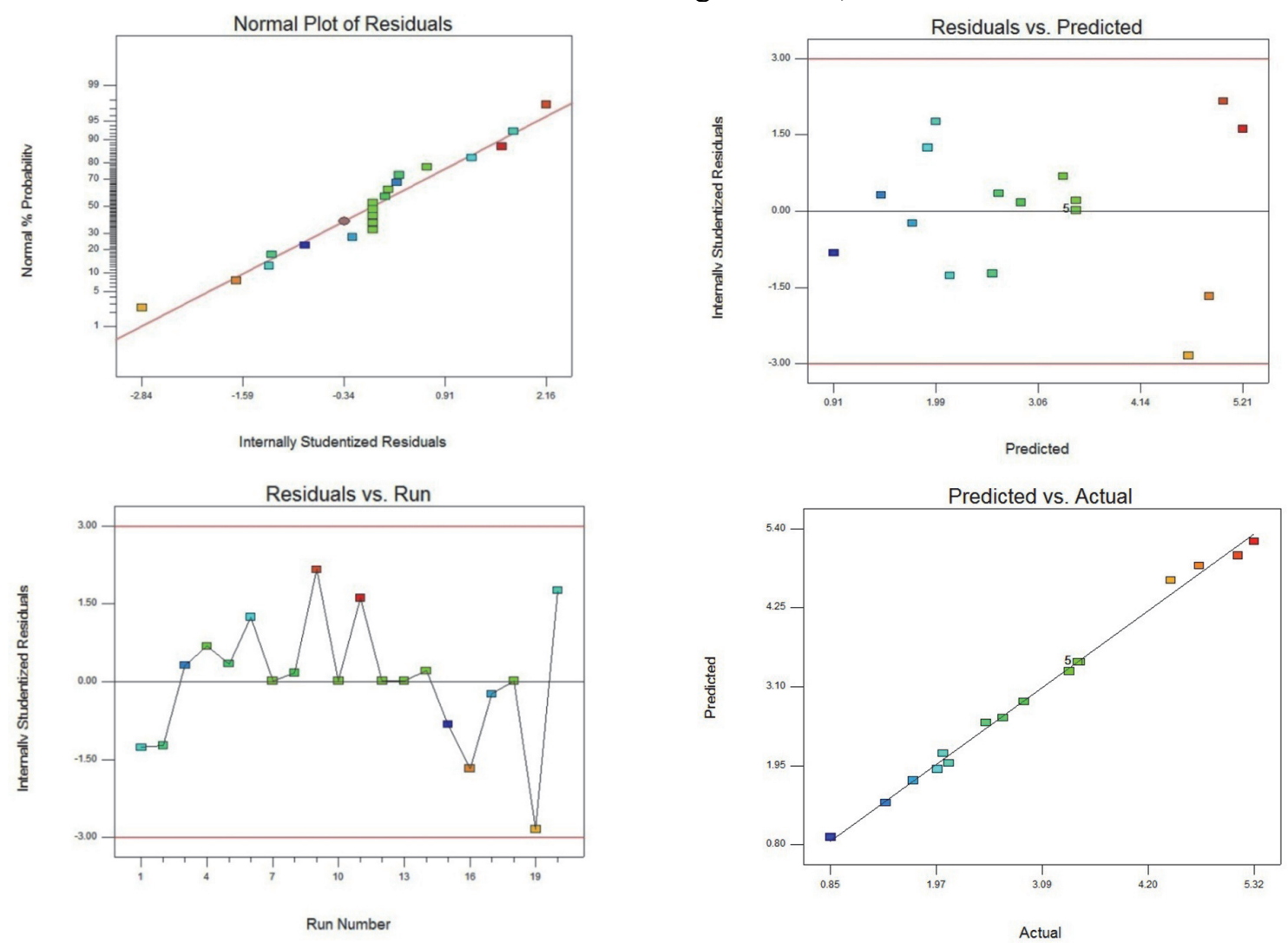

Fig. 5. Residual plots for surface roughness of post turning Al-Si alloy specimen 

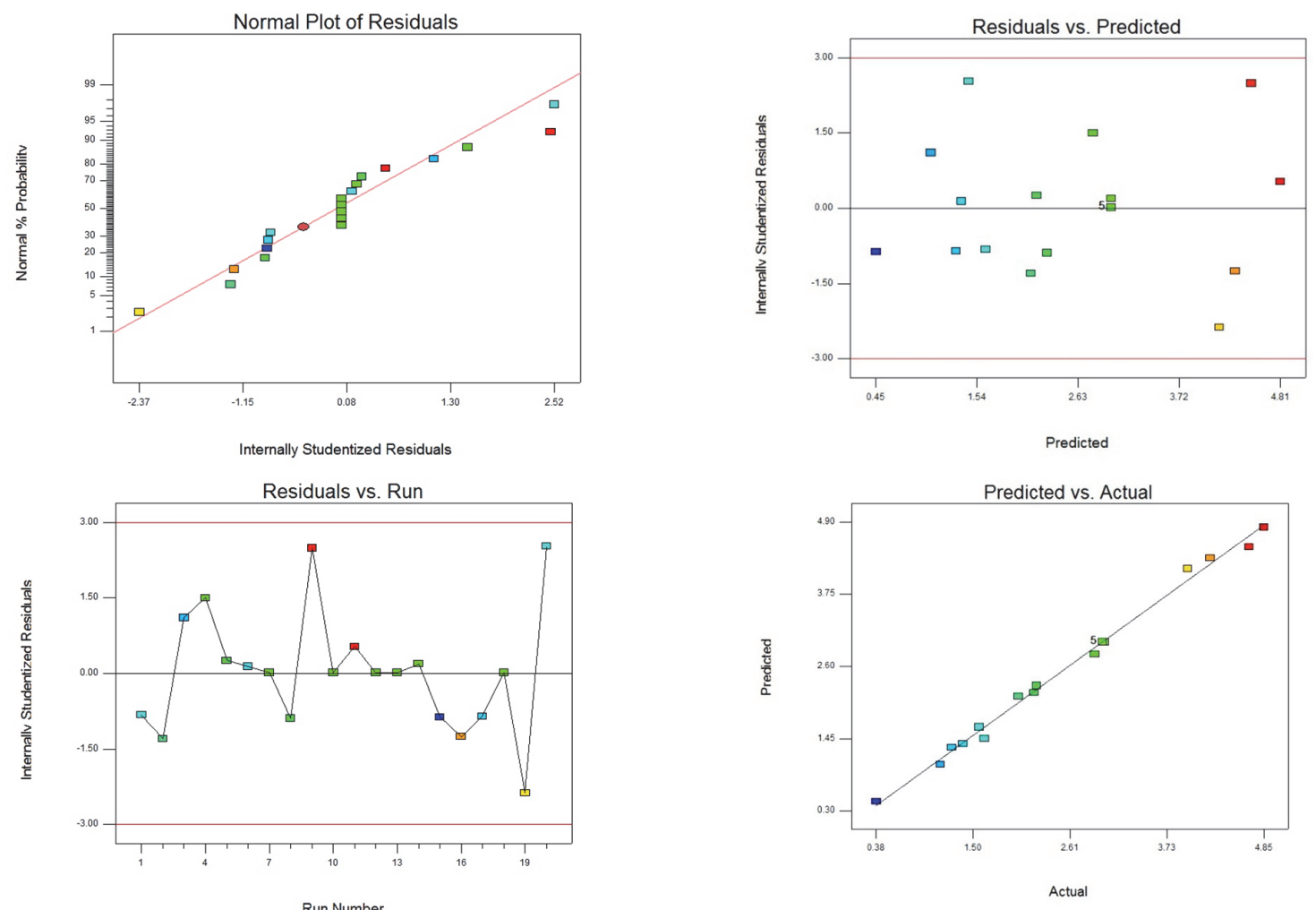

Fig. 6. Residual plots for surface roughness of post turning composite specimen
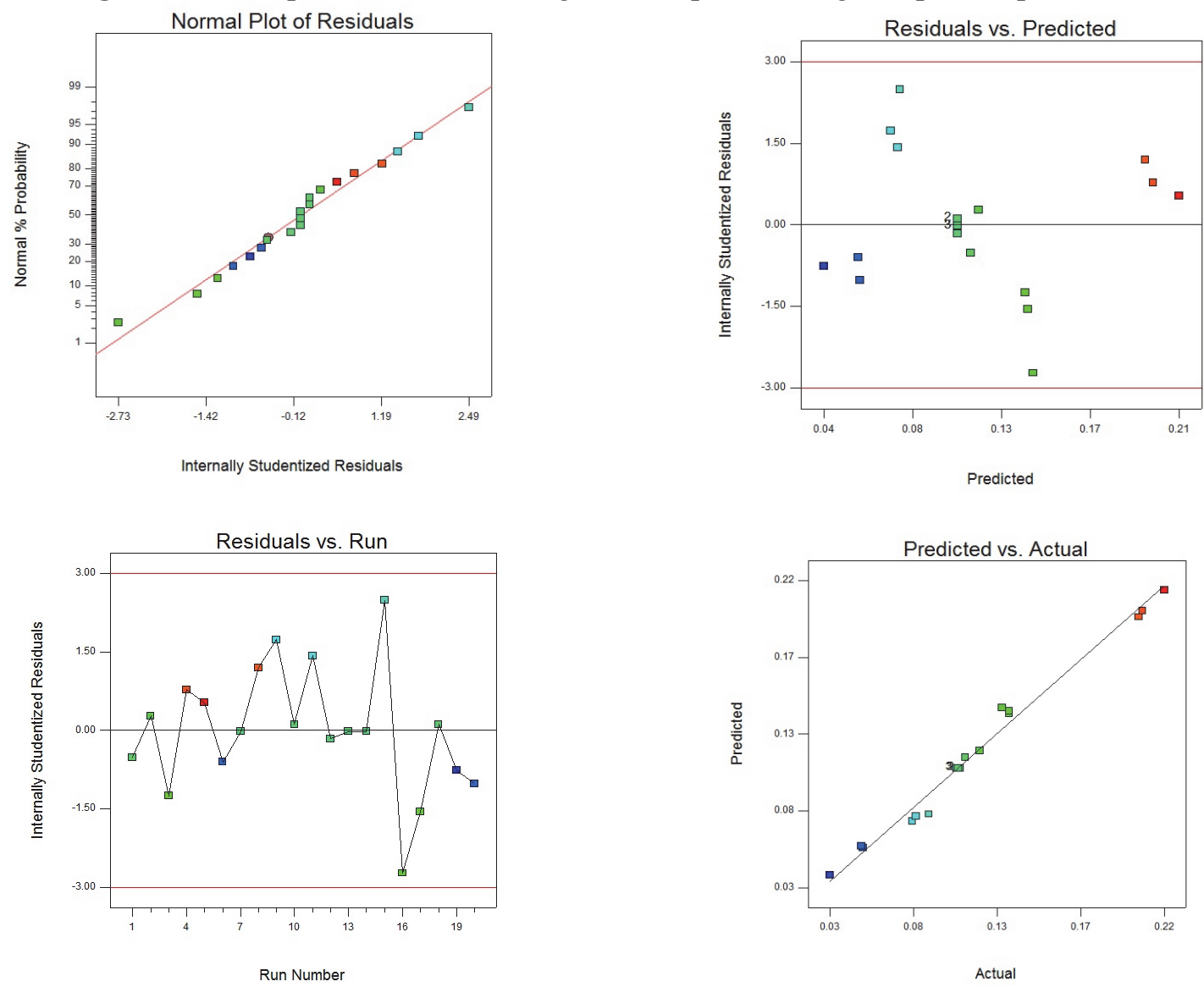

Fig. 7.Residual plots for tool wear of post turning Al-Si alloy specimen 

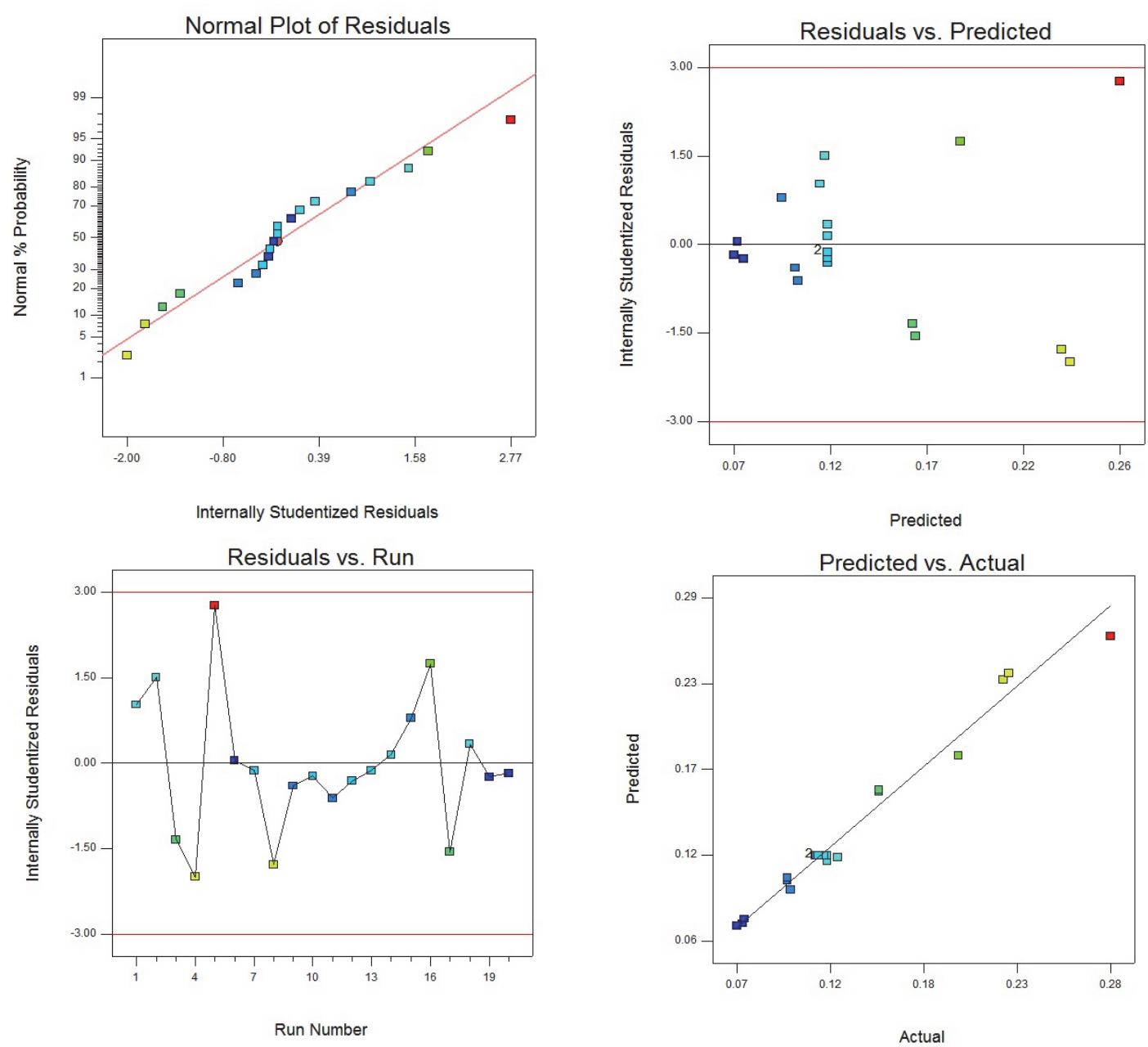

Fig. 8.Residual plots for tool wear of post turning composite specimen

The Independence of the data was tested, by plotting a graph between the residuals, and the run order for surface roughness and tool wear confirms that there is no predictable pattern observed, because all the run residues lay on or between the levels. The validity of these models was tested. For both the specimens, the predicted values of the response variables were fairly close to the corresponding experimental values. The models were adequate as represented by the points falling on a straight line in the normal probability plot. The errors were normally distributed confirmed a good-fit model. Also, the plot of the residuals versus the predicted surface roughness and tool wear is structure less i.e. containing no obvious pattern.

\subsubsection{Multiple linear regression models}

The surface roughness and tool wear models were developed by using the turning experiment data listed in Table 5 for the Al-Si Alloy and AMC.

\section{Surface roughness models:}

For Al-Si Alloy:

$$
S R=3.45-0.59 s+1.17 f+0.13 d-0.41 s f+0.06 s d+0.03 f d+0.06 s^{2}-0.20 f^{2}-0.39 d^{2}
$$

For AMC:

$$
S R=2.98-0.58 s+1.15 f+0.14 d-0.47 s f+0.04 s d+0.05 f d+0.06 s^{2}-0.21 f^{2}-0.39 d^{2}
$$




\section{Tool wear models}

For Al-Si Alloy:

$$
\begin{aligned}
& V B_{c}=0.104105+0.052997 s+0.019131 f+0.001717 d+0.010875 s f+0.00125 s d \\
& -0.00025 f d+0.0007947 s^{2}+0.00176 f^{2}+0.003174 d^{2}
\end{aligned}
$$

For AMC:

$$
\begin{aligned}
& V B_{c}=0.117331+0.057081 s+0.026077 f+0.001398 d+0.010375 s f+0.001875 s d \\
& -0.00037 f d+0.018726 s^{2}+0.007942 f^{2}-0.00072 d^{2},
\end{aligned}
$$

where, $s$ is cutting speed in the range between $90 \mathrm{~m} / \mathrm{min}$ to $150 \mathrm{~m} / \mathrm{min}, f$ is feed rate in the range between $0.07 \mathrm{~mm} / \mathrm{rev}$ to $0.21 \mathrm{~mm} / \mathrm{rev}, d$ is the depth of cut in the range between $0.2 \mathrm{~mm}$ to $0.6 \mathrm{~mm}$ and are the main effects of the process variables. The combined effect of process variables i.e. interaction between the process parameters such as $s$ and $f, s$ and $d$ or $f$ and $d$ show quantitative affect of process parameters on the surface roughness of the materials. The main effect of feed rate and depth of cut (i.e. coefficient attached to $f$ and $d$ ) are positive in values indicating that all these parameters increase surface roughness of the material. Whereas, the coefficient attached to cutting speed in value is negative. This means, it decreases surface roughness of the material. Out of the three parameters, feed rate has the greatest effect on the surface roughness of the material. The effect of feed is 2 fold higher in comparison to the effect of cutting speed and 9 fold higher in comparison to the effect of depth of cut, varied during the experiment. The surface roughness decreases with the increase in cutting speed up to certain level and the it increase with further increase in cutting speed, because of the creation of narrow grooves on the work piece. The temperature of the work piece has increased with the increase in cutting speed, which led to weaken the binding between the reinforcement and matrix. At higher value of feed and depth of cut the surface roughness of the material decreases. This is due to work hardening of the matrix material as well as confrontation of the rotating specimen with the debris produced by the chafing action of the bar against the carbide tool. For regression equation of the form $y=b_{0}+b_{1} X_{1}+b_{2} X_{2}+\ldots . .+b_{12} X_{1} X_{2}+b_{23} X_{2} X_{3}+\ldots \ldots+b_{1} X^{2}{ }_{1}+b_{2} X^{2}{ }_{2}+\ldots . b_{n} X_{n}^{2}, \mathrm{y}=$ response variable and $b_{1}, b_{2} \ldots . . b_{\mathrm{n}}$ are regression coefficients attached with process variables. $y=b_{0}$, When $X_{1}, X_{2} \ldots . . X_{\mathrm{n}}$ are $0 . b_{0}$ is the response of the material when the operating parameters are at their zero level. The zero level is also expressed as base level around which the variables are varied at two levels i.e. the highest level and the lowest level. In the present work $s, f$ and $d$ are varied between $90 \mathrm{~m} / \mathrm{min}-150 \mathrm{~m} / \mathrm{min}, 0.07 \mathrm{~mm} / \mathrm{rev}$ $-0.21 \mathrm{~mm} / \mathrm{rev}$ and $0.2 \mathrm{~mm}-0.6 \mathrm{~mm}$ respectively. The first column in the above Table 5 indicates $b_{0}$ value, which are positive response i.e. surface roughness value due to dry machining when all the input parameters are kept at their base level i.e. $(s=120 \mathrm{~m} / \mathrm{min}, f=0.14 \mathrm{~mm} / \mathrm{rev}$ and $d=0.4 \mathrm{~mm})$. Thus, if we insert 0 for $s, f$ and $d$ in equations, then the response of the three materials are expressed as surface roughness. That means for the combination of operating variables at $s=120 \mathrm{~m} / \mathrm{min}, f=0.14 \mathrm{~mm} / \mathrm{rev}$ and $d=0.4 \mathrm{~mm}$, computed $\mathrm{b}_{0}$ values are 3.45 for virgin Al-Si alloy in comparison to 2.98 for MMC reinforced with untreated fly ash.

Tables 12 and 13 show the experimental value at the base level as well as the value for $b_{0}$, calculated by using data shown in Table 5 for the surface roughness and tool wear respectively. It is observed from Tables 12 and 13, that there is a little difference between the experimental value and the calculated value. Thus, equations developed were accurate enough to predict amount of surface roughness and tool wear which would occur for any treatment combination of the process parameters in the range of variation of variables. The theoretical values and experimental values for surface roughness and tool wear are compared and reported in Tables 14 and 15. 
Table 12

Regression equation coefficients for the alloy and composite (surface roughness)

$\begin{array}{ccc}\text { Material } & \mathrm{b}_{\mathrm{o}} & \text { Main effect coefficient } \\ \text { Al-Si alloy } & +3.45 & s=-0.59 \\ & & f=+1.17 \\ & & d=+0.13 \\ \text { AMC } & +2.98 & s=-0.58 \\ & & f=+1.15 \\ d=+0.14\end{array}$

Table 13

Regression equation coefficients for the alloy and composite (tool wear)

\begin{tabular}{ccccc}
\hline Material & $b_{o}$ & \multicolumn{3}{c}{ Main effect coefficient } \\
\hline Al-Si Alloy & +0.104 & $s=+0.05229$ & $f=+0.01913$ & $d=+0.00171$ \\
AMC & +0.117 & $s=+0.05708$ & $f=+0.02607$ & $d=+0.00139$ \\
\hline
\end{tabular}

Table 14

Comparative value of surface roughness for two materials at base level

\begin{tabular}{lllccc}
\hline \multicolumn{1}{c}{ Material } & $\begin{array}{c}s \\
(\mathrm{~m} / \mathrm{min})\end{array}$ & $\begin{array}{c}f \\
(\mathrm{~mm} / \mathrm{rev})\end{array}$ & $\begin{array}{c}d \\
(\mathrm{~mm})\end{array}$ & $\begin{array}{c}\text { Theoretical value of } \\
\text { Surface Roughness }\end{array}$ & $\begin{array}{c}\text { Experimental value of } \\
\text { Surface Roughness }\end{array}$ \\
\hline Al-Si Alloy & 120 & 0.14 & 0.4 & +3.45 & +3.46 \\
AMC & 120 & 0.14 & 0.4 & +2.98 & +2.99 \\
\hline
\end{tabular}

Table 15

Comparative values of tool wear for two materials at base level

\begin{tabular}{llcccc}
\hline \multicolumn{1}{c}{ Material } & $\begin{array}{c}s \\
(\mathrm{~m} / \mathrm{min})\end{array}$ & $\begin{array}{c}f \\
(\mathrm{~mm} / \mathrm{rev})\end{array}$ & $\begin{array}{c}d \\
(\mathrm{~mm})\end{array}$ & $\begin{array}{c}\text { Theoretical value of } \\
\text { Flank wear }\end{array}$ & $\begin{array}{c}\text { Experimental value of } \\
\text { Flank wear }\end{array}$ \\
\hline Al-Si Alloy & 120 & 0.14 & 0.4 & +0.104 & +0.105 \\
AMC & 120 & 0.14 & 0.4 & +0.117 & +0.116 \\
\hline
\end{tabular}

\subsubsection{Confirmation test}

Confirmation tests were conducted to validate the statistical analysis by selecting experimental conditions that are different from those employed in the analysis. The parameters used in the confirmation test for surface roughness and tool wear are presented in Tables 16 and 17.

Table 16

Parameters used in the confirmation test for surface roughness

\begin{tabular}{cccc}
\hline Exp No & Cutting Speed $(\mathrm{m} / \mathrm{min})$ & $\begin{array}{c}\text { Feed Rate } \\
(\mathrm{mm} / \mathrm{rev})\end{array}$ & $\begin{array}{c}\text { Depth of cut } \\
(\mathrm{mm})\end{array}$ \\
\hline 1 & 100 & 0.07 & 0.3 \\
2 & 140 & 0.21 & 0.6 \\
\hline
\end{tabular}

Table 17

Parameters used in the confirmation test for tool wear

\begin{tabular}{cccc}
\hline Exp No & Cutting Speed(m/min) & $\begin{array}{c}\text { Feed Rate } \\
(\mathrm{mm} / \mathrm{rev})\end{array}$ & $\begin{array}{c}\text { Depth of cut } \\
(\mathrm{mm})\end{array}$ \\
\hline 1 & 100 & 0.07 & 0.3 \\
2 & 140 & 0.21 & 0.6 \\
\hline
\end{tabular}


The results of the confirmation tests are presented in Table 18 and Table 19. Experimental results are compared with the computed values developed from the regression models. Table 18 and Table 19 reveal that the experimental values and calculated values from the regression equation are nearly the same with the least error $( \pm 5 \%)$. The resulting equations are capable of predicting the surface roughness and tool flank wear to an acceptable level of accuracy.

Table 18

Results of the confirmation test for surface roughness

\begin{tabular}{ccccccc}
\hline Material & \multicolumn{3}{c}{ Experiment-1 } & \multicolumn{3}{c}{ Experiment-2 } \\
\cline { 2 - 6 } & \multicolumn{3}{c}{ Surface Roughness(Ra) } & \multicolumn{3}{c}{ Surface Roughness(Ra) } \\
\cline { 2 - 6 } & Model & Experiment & Error (\%) & Model & Experiment & Error(\%) \\
\hline Al-Si Alloy & 2.10 & 2.06 & 1.90 & 3.60 & 3.71 & -3.05 \\
AMC & 2.27 & 2.32 & -2.20 & 3.09 & 2.98 & 3.55 \\
\hline
\end{tabular}

Table 19

Results of the confirmation test for tool wear

\begin{tabular}{ccccccc}
\hline Material & \multicolumn{3}{c}{ Experiment-1 } & \multicolumn{3}{c}{ Experiment-2 } \\
\cline { 2 - 6 } & \multicolumn{3}{c}{ Flank wear $\left(V B_{c}\right)$} & \multicolumn{3}{c}{ Flank wear $\left(V B_{c}\right)$} \\
\cline { 2 - 7 } & Model & Experiment & Error (\%) & Model & Experiment & Error (\%) \\
\hline Al-Si Alloy & 0.062 & 0.064 & -3.2 & 0.176 & 0.171 & 2.8 \\
MMC(UFA) & 0.075 & 0.072 & 4.0 & 0.204 & 0.197 & 3.4 \\
\hline
\end{tabular}

Machined surface morphology of virgin Al-Si alloy and AMC reinforced with as received fly ash were examined by the optimum process parameters with the help of scanning electron microscope (SEM: JEOL, Model - JSM-6510 ) to reveal the surface texture as depicted in Fig. 9 and Fig. 10. The SEM image of the machined surface of the AMC reinforced with fly ash reveals that a relatively better surface finish is achieved compared with that of virgin Al-Si alloy, which has large feed marks. Given that the chips are broken by dispersed reinforcement particles during the machining of AMC composite at optimum conditions, the entrapment of chips between the work piece and tool was avoided. Therefore, BUE formation on the tool is prevented and the surface finish was enhanced.

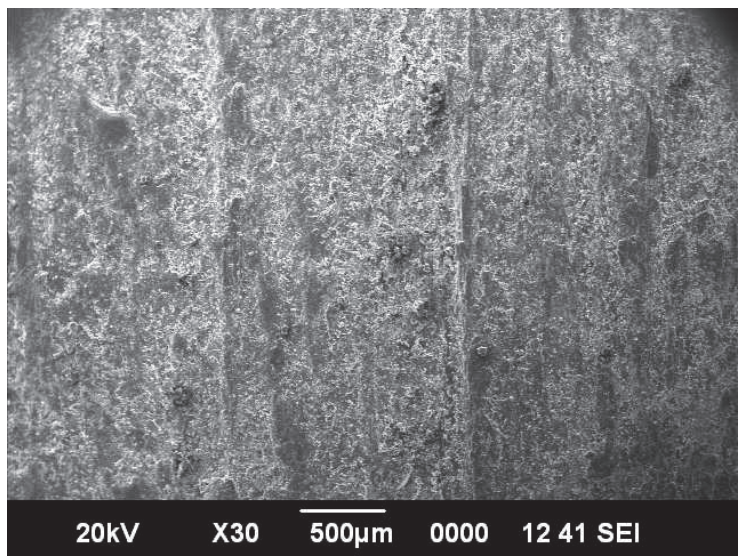

Fig. 9. SEM image of Al-Si alloy after machining

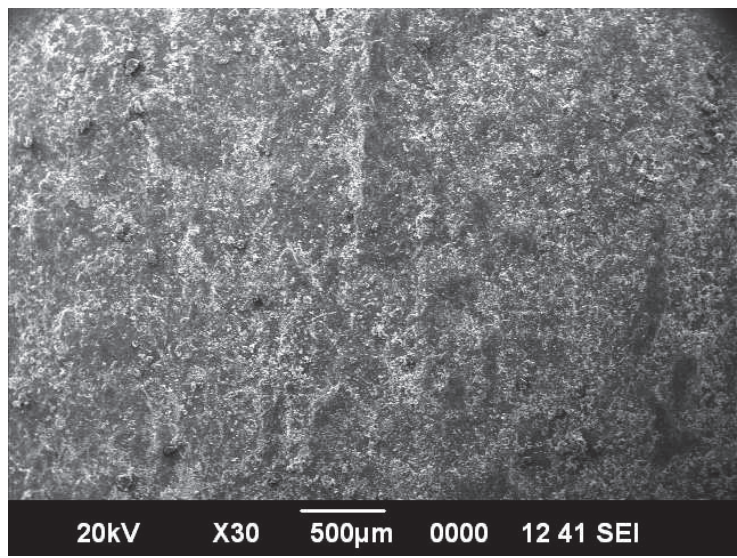

Fig. 10. SEM image of composite after machining 
The fly ash particles however are much smaller in size compared to size of chips in pure Al-Si alloy and hence do not cause much damage to the surface. Reddy et. al. (2013), Shanmughasundaram and Subramanian (2013) reported that the presence of the reinforcement enhances the machinability in terms of both surface roughness and lower tendency to clog the cutting tool, when compared to a non-reinforced Al alloy.

\section{Conclusions}

1. The metal matrix composite prepared with waste fly ash has shown better machining performance in comparison to that for virgin Al-Si alloy.

2. Low values of surface roughness and tool wear were obtained for AMC at all test conditions in comparison to that of Al-Si alloy.

3. Multiple regression predictive models were developed to predict the machining responses such as surface roughness and tool wear of the AMC reinforced with waste fly ash. Good agreements between the predicted and actual responses were observed.

4. ANOVA results indicated that the values of coefficient of determination $R^{2}$ were nearly equal to 1. The adjusted coefficient of determination $R^{2}$ was variation of the ordinary $R^{2}$ statistic that reflected the number of factors in the model. The entire adequacy measured was closer to 1 , which was in reasonable agreement and indicated adequate models.

5. Confirmation experiments revealed that the experimental values and calculated values from the regression equation are nearly the same with the least error $( \pm 5 \%)$. The resulting equations are capable of predicting the surface roughness and tool flank wear to an acceptable level of accuracy.

6. The SEM image of the machined surface for AMC reported a relatively better surface finish compared to that of virgin Al-Si alloy, which had large feed marks.

\section{Funding}

Support of this work under DST/MERC, Govt of India, New Delhi core research funding is gratefully acknowledged.

\section{Acknowledgement}

The authors acknowledge the assistance of the Department of Science and Technology (DST), Govt of India, New Delhi and KIIT University, India for the composite fabrication and machining equipments.

\section{References}

Anasyida, A. S., Daud, A. R., \& Ghazali, M. J. (2010). Dry sliding wear behavior of Al-12Si-4Mg alloy with cerium addition. Materials and Design, 31(1), 365-374.

Banerjee, S., Mahapatro, D., \& Dubey, S. (2009). Some study on electrical discharge machining of $(\{\mathrm{WC}+\mathrm{TiC}+\mathrm{TaC} / \mathrm{NbC}\}-\mathrm{Co})$ cemented carbide. The International Journal of Advanced Manufacturing Technology, 43(11-12), 1177-1188.

Bienia, J., Walczak, M., Surowska, B., \& Sobczaka, J. (2003). Microstructure and corrosion behavior of aluminum fly ash composites. Journal of Optoelectronics and Advanced Materials, 5(2), 493-502.

Box, G. E., \& Hunter, J. S. (1957). Multi-factor experimental designs for exploring response surfaces. The Annals of Mathematical Statistics, 28(1), 195-241.

Charles, S., Arunachalam, V. P., \& Subramanian, R. (2006). Property analysis and mathematical modeling of machining parameters of aluminum hybrid composites fabricated by powder metallurgy. Journal of Advanced Materials, 38(4), 25-34. 
Cochran, W. G., \& Cox, G. M.(1957). Experimental Designs. John Wiley and Sons, New York.

Dou, Z., Wu, G., Huang, X., Sun, D., \& Jiang, L. (2007). Electromagnetic shielding effectiveness of aluminum alloy-fly ash composites. Composites Part A: Applied Science and Manufacturing, 38(1), $186-191$

Li, X., \& Seah, W. K. H. (2001). Tool wear acceleration in relation to workpiece reinforcement percentage in cutting of metal matrix composites. Wear, 247(2), 161-171.

Manna, A., \& Bhattacharayya, B. (2005). Influence of machining parameters on the machinability of particulate reinforced $\mathrm{Al} / \mathrm{SiC}-\mathrm{MMC}$. The International Journal of Advanced Manufacturing Technology, 25(9), 850-856.

Mishra, P., Das, D., Ukamanal, M., Routara, B., \& Sahoo, A. (2015). Multi-response optimization of process parameters using Taguchi method and grey relational analysis during turning AA 7075/SiC composite in dry and spray cooling environments. International Journal of Industrial Engineering Computations, 6(4), 445-456.

Montgomery, D.C. (1990). Introduction to statistical quality control. Wiley, New York.

Montgomery, D. C. \& Peck, E. A. (1992). Introduction to linear regression analysis, Wiley, New York.

Prakash, J. U., Moorthy, T. V., \& Peter, J. M. (2013). Experimental investigations on machinability of aluminium alloy (A413)/Flyash/B ${ }_{4} \mathrm{C}$ hybrid composites using wire EDM. Procedia Engineering, 64, 1344-1353.

Rao, C. P., Bhagyashekar, M. S., \& Viswanath, N. (2014). Machining behavior of Al6061-flyash composites. Procedia Materials Science, 5, 1593-1602.

Reddy, S. M., Chetty, S. V., \& Premkumar, S. (2013). Evaluation of mechanical and wear properties of Al 7075, flyash and E-glass fibre-reinforced hybrid metal matrix composites. Indian Foundry Journal, 59(2), 27-32.

Rohatgi, P. K., Kim, J. K., Gupta, N., Alaraj, S., \& Daoud, A. (2006). Compressive characteristics of A356/fly ash cenosphere composites synthesized by pressure infiltration technique. Composites Part A: Applied Science and Manufacturing, 37(3), 430-437.

Rohatgi, P. K., Gajdardziska-Josifovska, M., Robertson, D. P., Kim, J. K., \& Guo, R. Q. (2002). Agehardening characteristics of aluminum alloy-hollow fly ash composites. Metallurgical and Materials Transactions A, 33(5), 1541-1547.

Rohatgi, P. K., Weiss, D., \& Gupta, N. (2006). Applications of fly ash in synthesizing low-cost MMCs for automotive and other applications. JOM, 58(11), 71-76.

Saheb, N., Laoui, T., Daud, A. R., Harun, M., Radiman, S., \& Yahaya, R. (2001). Influence of Ti addition on wear properties of Al-Si eutectic alloys. Wear, 249(8), 656-662.

Sahoo, A. K., Pradhan, S., \& Rout, A. K. (2013). Development and machinability assessment in turning $\mathrm{Al} / \mathrm{SiCp}$-metal matrix composite with multilayer coated carbide insert using Taguchi and statistical techniques. Archives of Civil and Mechanical Engineering, 13(1), 27-35.

Senapati, A. K., Mishra, P. C., Routray, B. C., \& Ganguly, R. I. (2015). Mechanical behavior of aluminium matrix composite reinforced with untreated and treated waste fly ash. Indian Journal of Science and Technology, 8(S9), 111-118.

Shanmughasundaram, P., \& Subramanian, R. (2013). Wear behavior of eutectic Al-Si alloy-graphite composites fabricated by combined modified two-stage stir casting and squeeze casting methods. Advances in Materials Science and Engineering, 2013.

Shanmughasundaram, P., \& Subramanian, R. (2013). Influence of graphite and machining parameters on the surface roughness of Al-fly ash/graphite hybrid composite: a Taguchi approach. Journal of Mechanical Science and Technology, 27(8), 2445-2455.

Surappa, M. K. (2008). Synthesis of fly ash particle reinforced A356 Al composites and their characterization. Materials Science and Engineering: A, 480(1), 117-124.

Wu, G. H., Dou, Z. Y., Jiang, L. T., \& Cao, J. H. (2006). Damping properties of aluminum matrix-fly ash composites. Materials Letters, 60(24), 2945-2948. 
(C) 2016 by the authors; licensee Growing Science, Canada. This is an open access article distributed under the terms and conditions of the Creative Commons Attribution (CCBY) license (http://creativecommons.org/licenses/by/4.0/). 